\title{
Application of dissociation curve analysis to radiation hybrid panel marker scoring: generation of a map of river buffalo (B. bubalis) chromosome 20
}

\author{
Kelli J Kochan ${ }^{1}$, M Elisabete J Amaral ${ }^{2}$, Richa Agarwala ${ }^{3}$, \\ Alejandro A Schäffer ${ }^{3}$ and Penny K Riggs*1
}

Address: ${ }^{1}$ Department of Animal Science, Texas A\&M University, College Station, Texas, USA, ${ }^{2}$ Departamento de Biologia, Instituto de Biociências, Letras e Ciências Exatas (IBILCE), Universidade Estadual Paulista (UNESP), Campus de São José do Rio Preto, São Paulo, Brasil and ${ }^{3}$ National Center for Biotechnology Information, National Institutes of Health, Department of Health and Human Services, Bethesda, Maryland, USA

Email: Kelli J Kochan - kkochan@tamu.edu; M Elisabete J Amaral - eamaral@ibilce.unesp.br; Richa Agarwala - richa@helix.nih.gov; Alejandro A Schäffer - schaffer@helix.nih.gov; Penny K Riggs* - riggs@tamu.edu

* Corresponding author

Published: 17 November 2008

BMC Genomics 2008, 9:544 doi:10.1 |86/147|-2164-9-544
Received: 17 June 2008

Accepted: 17 November 2008

This article is available from: http://www.biomedcentral.com/I47I-2/64/9/544

() 2008 Kochan et al; licensee BioMed Central Ltd.

This is an Open Access article distributed under the terms of the Creative Commons Attribution License (http://creativecommons.org/licenses/by/2.0), which permits unrestricted use, distribution, and reproduction in any medium, provided the original work is properly cited.

\begin{abstract}
Background: Fluorescence of dyes bound to double-stranded PCR products has been utilized extensively in various real-time quantitative PCR applications, including post-amplification dissociation curve analysis, or differentiation of amplicon length or sequence composition. Despite the current era of whole-genome sequencing, mapping tools such as radiation hybrid DNA panels remain useful aids for sequence assembly, focused resequencing efforts, and for building physical maps of species that have not yet been sequenced. For placement of specific, individual genes or markers on a map, low-throughput methods remain commonplace. Typically, PCR amplification of DNA from each panel cell line is followed by gel electrophoresis and scoring of each clone for the presence or absence of PCR product. To improve sensitivity and efficiency of radiation hybrid panel analysis in comparison to gel-based methods, we adapted fluorescence-based real-time PCR and dissociation curve analysis for use as a novel scoring method.

Results: As proof of principle for this dissociation curve method, we generated new maps of river buffalo (Bubalus bubalis) chromosome 20 by both dissociation curve analysis and conventional marker scoring. We also obtained sequence data to augment dissociation curve results. Few genes have been previously mapped to buffalo chromosome 20, and sequence detail is limited, so 65 markers were screened from the orthologous chromosome of domestic cattle. Thirty bovine markers (46\%) were suitable as cross-species markers for dissociation curve analysis in the buffalo radiation hybrid panel under a standard protocol, compared to 25 markers suitable for conventional typing. Computational analysis placed 27 markers on a chromosome map generated by the new method, while the gel-based approach produced only 20 mapped markers. Among 19 markers common to both maps, the marker order on the map was maintained perfectly.

Conclusion: Dissociation curve analysis is reliable and efficient for radiation hybrid panel scoring, and is more sensitive and robust than conventional gel-based typing methods. Several markers could be scored only by the new method, and ambiguous scores were reduced. PCR-based dissociation curve analysis decreases both time and resources needed for construction of radiation hybrid panel marker maps and represents a significant improvement over gel-based methods in any species.
\end{abstract}




\section{Background}

In addition to quantification of mRNA after reverse transcription, real-time quantitative polymerase chain reaction (qPCR) technology has been utilized for diverse applications including detection and quantification of bacterial or viral pathogens $[1,2]$, detection of mRNA splice variants [3], and quantification of transgene copy numbers [4]. Fluorescence-based dissociation curve analysis has been used for detection of DNA sequence polymorphisms from large deletions [5] to single nucleotide polymorphisms [6].

Since development of methods to construct marker maps via radiation hybrid (RH) somatic cell culture panels [79], RH mapping has become a method of choice. For large mammals, the generation interval and animal husbandry costs make construction of genetic maps expensive and lengthy endeavors. Many livestock species, particularly those important in countries where resources for genetic evaluation and improvement are scarce, can benefit greatly from continued mapping efforts. For species whose genomes have been sequenced, RH mapping remains a useful tool to aid assembly of sequence scaffolds [10]. Methods for construction of whole-genome RH mapping panels have been described in detail previously [11], and to date, whole-genome RH mapping panels have been produced for livestock animals including pig [12] chicken [13], horse [14], cattle [15,16], sheep [17] and river buffalo [18]. As livestock, river buffalo (Bubalus bubalis) provide a source of meat, dairy products, and draught power throughout the world including Asia, South America, the Mediterranean, and other regions (reviewed in Boyazaglu [19], Bernardes, [20] and Cruz [21]). This species can benefit from the same selection and mapping efforts that have been applied to domestic cattle [22].

Once an RH panel is constructed, development of maps involves three major steps: 1) marker development, 2) marker scoring, and 3) computation of optimal marker order. The availability of genome sequences from related organisms has speeded marker development [23], and new software for computing RH maps [24] makes computation fast, leaving marker scoring as the major time bottleneck in construction of RH maps. Gel-based methods (e.g., $[25,26])$ are labor intensive, and in cases where PCR products can be amplified from both donor and recipient DNA, products must usually be differentiated on the basis of size. Here we demonstrate the novel application of qPCR technology and dissociation curve analysis as a rapid and robust method for typing radiation hybrid panel DNA, and construct a map of river buffalo (Bubalus bubalis) chromosome 20 (BBU20) as proof of principle.

\section{Results \\ Initial marker testing}

River buffalo chromosome 20 is orthologous to domestic cattle (Bos taurus) chromosome 21 (BTA21; [27]). Significant sequence conservation between river buffalo and cattle allows new buffalo maps to be generated from bovine markers [28]. To rapidly generate a map of BBU20, we took advantage of the existing published BTA21 marker map to identify PCR primers that could be used for mapping in buffalo. We chose primers for 65 markers or genes that were derived from cattle sequence and had been previously mapped to BTA21. To determine suitability for RH panel typing, we screened primer pairs by PCR-amplification of DNA from river buffalo (the RH panel donor animal), A23 hamster (the RH panel recipient cell line), and cattle (positive control) fibroblast cells, followed by dissociation curve analysis of the products as described by Ririe et al. [29]. Of 65 marker primer sets, 31 markers were suitable for further analysis because they amplified river buffalo DNA well, exhibited dissociation curves that differed between the river buffalo and hamster products, and produced single product bands when checked by gel electrophoresis (Table 1). The remaining markers were discarded because they produced more than one river buffalo band, could not differentiate hamster and buffalo PCR products, or did not amplify. For more detailed explanation, see Additional File 1 and 2. Most of the primers used came from previously published bovine maps, and PCR optimization was not conducted because our objective was to implement a standardized GPCR protocol for screening and analysis to develop a rapid and efficient mapping method. We also compared data from manually prepared 96-well reactions to semi-automated robot-prepared 384well reaction plates and obtained comparable results (not shown).

\section{Comparison of dissociation curve and gel-based typing methods}

We typed 31 markers in a panel of 90 RH clones. Twentyfour markers were easily typed on the RH panel by both qPCR and gel electrophoresis, meaning that both agarose gels and dissociation curves resulted in clear differentiation of hamster and buffalo PCR products from individual hybrid clones. Of the 24 markers typed by both methods, 19 were scored unambiguously in all $90 \mathrm{RH}$ clones and exhibited perfect accord between the two methods. Sample gel images and dissociation curves are shown in Figure 1 . The remaining 5 markers were scored consistently by both methods in the majority of the RH clones, but 1 to 3 clones (out of 90) were scored as questionable (not clearly positive or negative for the product of interest) by one or the other method.

An additional 6 markers (25\% increase) could be scored for mapping by the qPCR method alone under the 
Table I: Markers chosen for mapping analysis

\begin{tabular}{|c|c|c|c|}
\hline Marker ID & Marker Type & Primer Sequence & Primer Reference \\
\hline AGLA233 & microsatellite & $\begin{array}{l}\text { F: } 5 \text { '-tgcaaacatccacgtagcataaata } \\
\text { R: } 5 \text { '-gcatgaacagccaatagtgtcatc }\end{array}$ & {$[40]$} \\
\hline AKT-I & STS/gene & $\begin{array}{l}\text { F: 5'-cacctgaccaagacgacagcat } \\
\text { R: } 5 \text { '-cgaggttccactcaaacgcatc }\end{array}$ & UniSTS: 277959; Accession\# X61036 \\
\hline AKT-2 & microsatellite & $\begin{array}{l}\text { F: } 5 \text { '-tgcccattcccagagccctgt } \\
\text { R: } 5 \text { '-cagctcgccccagggtgg }\end{array}$ & {$[41]$} \\
\hline BM34I3 & microsatellite & $\begin{array}{l}\text { F: 5'-tccctggtaaccaatgaattc } \\
\text { R: } 5 \text { '-caatggatttgaccctccc }\end{array}$ & {$[42]$} \\
\hline BMC522I & microsatellite & $\begin{array}{l}\text { F: 5'-agcaaggagaacaggcattc } \\
\text { R: 5'-cttctttggcagcacagtttc }\end{array}$ & {$[42]$} \\
\hline BMSI494 & microsatellite & $\begin{array}{l}\text { F: } 5 \text { '-tctggagctgcaaaagacc } \\
\text { R: } 5 \text { '-aatggatgactcctggatgg }\end{array}$ & {$[43]$} \\
\hline BMSI56I & microsatellite & $\begin{array}{l}\text { F: } 5 \text { '-acccacatgttgggagg } \\
\text { R: } 5 \text { '-agggaaaggccaaagcac }\end{array}$ & Stone, 1996 (unpublished) Accession\# GI8764 \\
\hline BMS2382 & microsatellite & $\begin{array}{l}\text { F: } 5 \text { '-agcacggagtcgttgtctg } \\
\text { R: } 5 \text { '-ccatctggacagaacgttacc }\end{array}$ & {$[44]$} \\
\hline BMS868 & microsatellite & $\begin{array}{l}\text { F: } 5 \text { '-tcatccaaccatctcatcct } \\
\text { R: } 5 \text { '-acatggaaacgaacctacattc }\end{array}$ & [43] \\
\hline CC530547 & STS/gene & $\begin{array}{l}\text { F: 5'-tgatggattacctgatgcttcttgc } \\
\text { R: } 5 \text { '-tcaaccacagtcttgcttgctttc }\end{array}$ & UniSTS: 476716 \\
\hline CHGA & STS/gene & $\begin{array}{l}\text { F: } 5 \text { '-cccttgcctttcaacgattatct } \\
\text { R: 5'-tcaggagtcctcagctttcacc }\end{array}$ & $\begin{array}{l}\text { F: new design from Accession\# NC_007319.2 (5199500352008294) } \\
\text { R: UniSTS: } 278198\end{array}$ \\
\hline DIK2II6 & microsatellite & $\begin{array}{l}\text { F: } 5 \text { '-cagccacaactggaactcg } \\
\text { R: 5'-gggtcggttgcatcacat }\end{array}$ & {$[40]$} \\
\hline DIK2367 & microsatellite & $\begin{array}{l}\text { F: } 5 \text { '-tgctctatgaatcccaagctg } \\
\text { R: } 5 \text { '-cctcgttttatggctgtgct }\end{array}$ & {$[40]$} \\
\hline DIK2586 & microsatellite & $\begin{array}{l}\text { F: } 5 \text { '-ggacgctgacttggaaggta } \\
\text { R: } 5 \text { '-caccaacccttgtttccagt }\end{array}$ & {$[40]$} \\
\hline DIK282I & microsatellite & $\begin{array}{l}\text { F: } 5 \text { '-cctttctgtcgtctcccttg } \\
\text { R: } 5 \text { '-tccttggagggttttgtcc }\end{array}$ & {$[40]$} \\
\hline DIK2849 & microsatellite & $\begin{array}{l}\text { F: } 5 \text { '-cacagacgagatcagctcca } \\
\text { R: } 5 \text { '-ccgataattgtccccaacag }\end{array}$ & {$[40]$} \\
\hline DIK300I & microsatellite & $\begin{array}{l}\text { F: 5'-ctcggggccaaaaaccaaaaccta } \\
\text { R: } 5 \text { '-tccgagataaagtacagaaagtcc }\end{array}$ & {$[40]$} \\
\hline DIK3009 & microsatellite & $\begin{array}{l}\text { F: } 5 \text { '-tggggcccggaggagtggtg } \\
\text { R: 5'-gatgttcgagggctttct }\end{array}$ & {$[40]$} \\
\hline DIK3023 & microsatellite & $\begin{array}{l}\text { F: } 5 \text { '-tcttgccacctttggcttt } \\
\text { R: } 5 \text { '-gaggcgtgatgacgtgtcca }\end{array}$ & {$[40]$} \\
\hline DIK4322 & microsatellite & $\begin{array}{l}\text { F: } 5 \text { '-tccatagtgccagtgagctg } \\
\text { R: } 5 \text { '-ggagcgtccaaagataacca }\end{array}$ & {$[40]$} \\
\hline DIK4894 & microsatellite & $\begin{array}{l}\text { F: } 5 \text { '-ccagctttcttcctttacagtg } \\
\text { R: } 5 \text {-caatccttggactgggaaga }\end{array}$ & {$[40]$} \\
\hline GRP58 & STS/gene & $\begin{array}{l}\text { F: } 5 \text { '-gaaactccattttgctgtag } \\
\text { R: } 5 \text {--aacccacgctaacttgtaac }\end{array}$ & new design from Accession\# NC_0073I9.2 (490I848I49040683) \\
\hline IDVGA-39 & microsatellite & $\begin{array}{l}\text { F: 5'-acggtgggaacatcttgtcacta } \\
\text { R: } 5 \text { '-ccagtattcttcctgcgaaaaatc }\end{array}$ & {$[45]$} \\
\hline IGFIR & STS/gene & $\begin{array}{l}\text { F: } 5 \text { '-ggaacatggtggacgtggac } \\
\text { R: } 5 \text { '-gatgcgttggtgcgaatgta }\end{array}$ & new design from Accession\# NC_0073 I 9.2 (93003629360647) \\
\hline ILSTS054 & microsatellite & $\begin{array}{l}\text { F: } 5 \text { '-gaggatcttgattttgatgtcc } \\
\text { R: } 5 \text { '-agggccactatggtacttcc }\end{array}$ & {$[46]$} \\
\hline ILSTS092 & microsatellite & $\begin{array}{l}\text { F: } 5 \text { '-gagaaactttgggctgctgc } \\
\text { R: } 5 \text { '-atggattgcttctgtggacc }\end{array}$ & [46] \\
\hline MBIP & STS/gene & $\begin{array}{l}\text { F: } 5 \text { '-actattcactggctgaacttg } \\
\text { R: } 5 \text { '-atggaaggtgacgtgttg }\end{array}$ & UniSTS: 278723 \\
\hline MFGE8 & STS/gene & $\begin{array}{l}\text { F: 5'-ggcacaaccgtatcacc } \\
\text { R: 5'-tccatcccagacctactcag }\end{array}$ & new design from Accession\# NC_007319.2 (2021 I01820195989) \\
\hline MULGE4 & microsatellite & $\begin{array}{l}\text { F: } 5 \text { '-gcaacccttctgatgtcatgaacc } \\
\text { R: } 5 \text { '-aaaagcacaactcccctcaaatcc }\end{array}$ & [47] \\
\hline RMI5I & microsatellite & $\begin{array}{l}\text { F: 5'-cccagaggtgacaacatttccag } \\
\text { R: 5'-gatccaccaaaaaccagctgga }\end{array}$ & {$[48]$} \\
\hline SERPINAI & STS/gene & $\begin{array}{l}\text { F: 5'-aagaacctgtatcactccgaagc } \\
\text { R: 5'-tgtgtttgggtcaagaacctttac }\end{array}$ & new design from Accession\# NC_0073I9.2 (525906225259999I) \\
\hline
\end{tabular}


described experimental reaction conditions. For 3 markers (BMS1494, IGF1R and ILSTS092), discrete and scorable dissociation curves were clearly seen, but agarose gel electrophoresis of PCR products resulted in bands that were

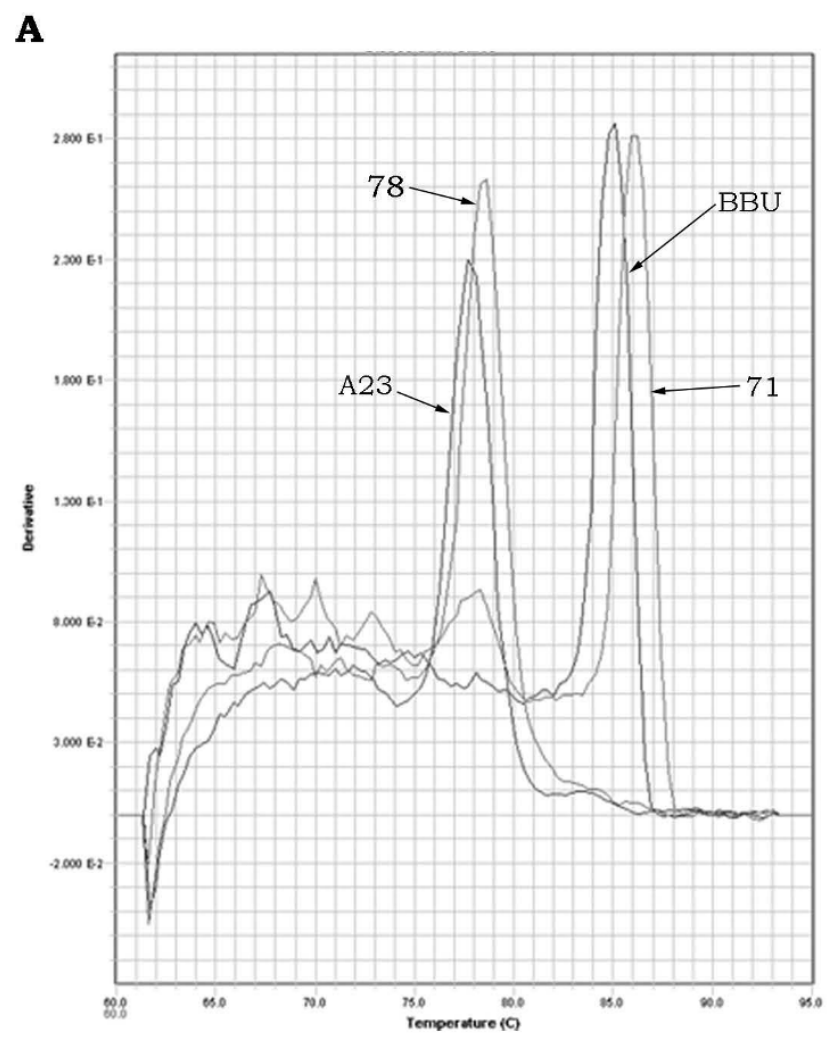

B

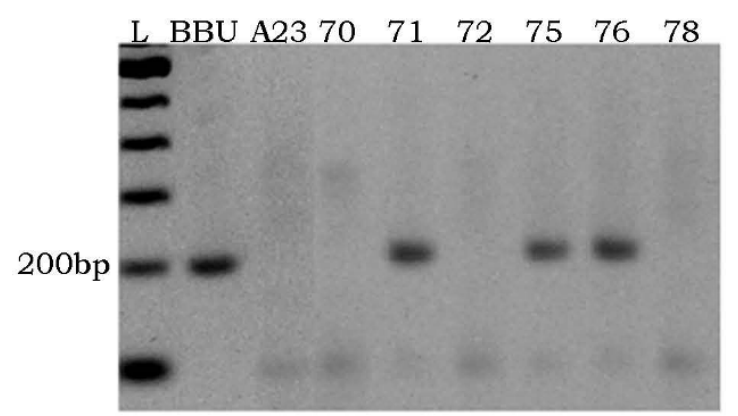

\section{Figure I}

Marker typing by qPCR and conventional method. Dissociation curve (A) and gel image (B) of DIK2849 as an example of unambiguous + /- scoring of clones by both dissociation curve and agarose gel electrophoresis in buffalo (BBU), hamster (A23) and selected RH clones. In (A), the dissociation curve is plotted as the first derivative of fluorescence relative to temperature in the SDS software view. Clones \#7 I (positive for BBU DNA) and \#78 (negative for BBU DNA) are indicated along with hamster negative control and buffalo positive control. Peaks are easily differentiated for scoring. indistinguishable between river buffalo and hamster (Figure 2). Sequence analysis of these markers [GenBank: BV727772, BV727773, BV727774, BV727775, BV727776 and BV727777] indicated that their PCR products actually differed in size by 1 to $6 \mathrm{bp}$ between river buffalo and hamster. Sequence composition of the products also differed between the two species, resulting in different melting temperatures that could be readily scored (Figure 3 ). The remaining primer sets (DIK2367, DIK4322 and RM151) amplified so weakly that bands were too faint for reliable gel-based visual scoring, but signals observed by dissociation curve analysis were easily scored (Figure 4). In particular, $R M 151$ produced a very strong primer-dimer band that overwhelmed the gel image, while the dissociation curve contained distinct peaks that readily distinguished the primer-dimer from the actual product.

A

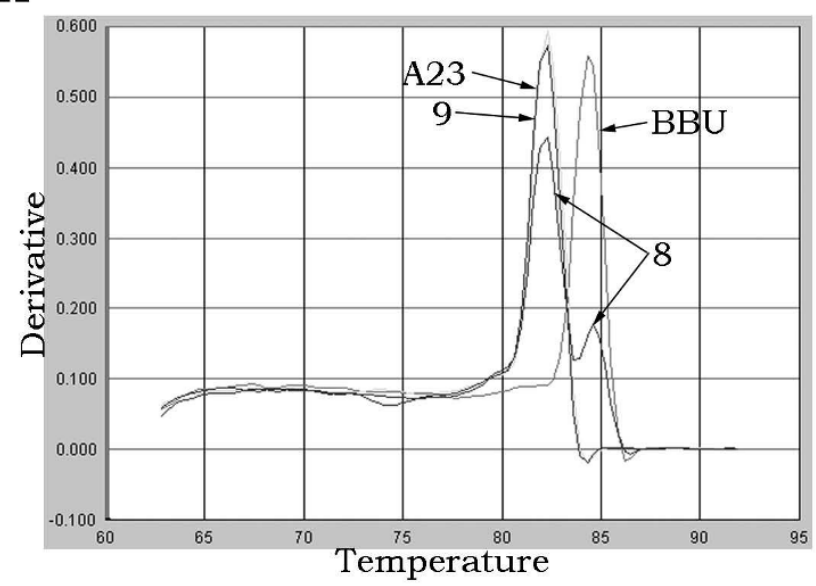

B

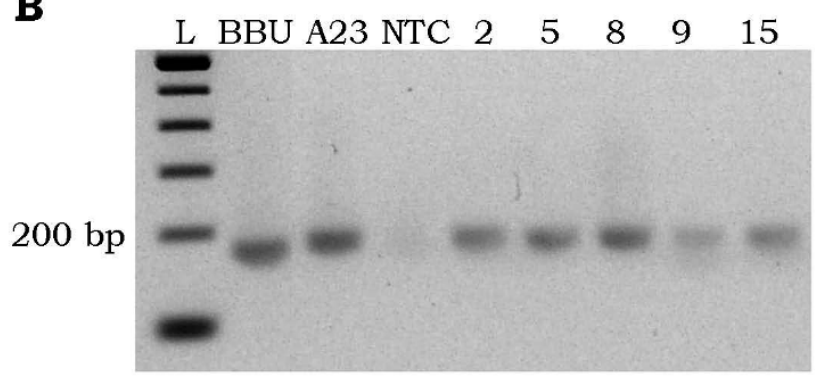

Figure 2

Differentiation of similarly-sized products by $q P C R$. Dissociation curve (A) and gel image (B) of IGFIR in buffalo (BBU), hamster (A23), no-template control (NTC) and selected $\mathrm{RH}$ clones. River buffalo and hamster products are indistinguishable on agarose gels, but are easily separated by differential dissociation curve analysis. Note that in clones positive for buffalo DNA (e.g. \#8) hamster DNA is also amplified, as expected. 


\section{A23 GGAACATGGTGGACGTGGACCTACCTCCCAACAAGGAGGGGGAGCCTGGCATTTTACTGC BBU GGAACATGGTGGACGTGGACCTTCCGCCCAACAAGGACGTGGAGCCCGGCATTTTGCTGC

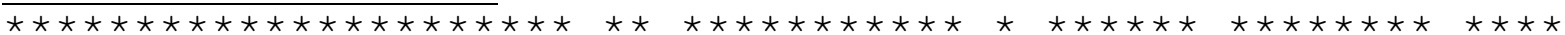 \\ A23 AtgGgCTGAAGCCCTGGACCCAGTATGCCGTCTATGTCAAGGCTGTGACCCTCACCATGG BBU ACGGGCTGAAGCCCTGGACGCAGTACGCCGTTTACGTGAAGGCCGTGACCCTCACCATGG

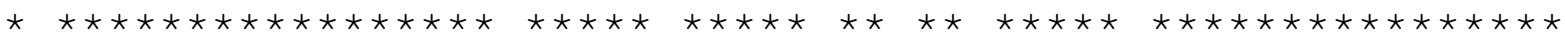
A23 TGGAAAACGACCATATCCGTGGGGCCAAAAGTATGGAAATCTTGTACATTCGCACCAACG BBU TGGAGAACGACCACATTCGTGGGGCCAAGAGC---GAGATCTTGTACATTCGCACCAACG

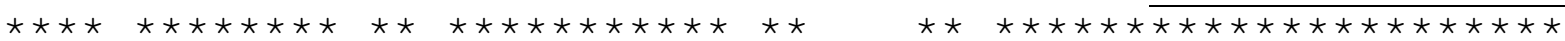

$\begin{array}{llll}\text { A23 } & \text { CATC } & 184 \mathrm{bp} & \mathrm{Tm}=86.9^{\circ} \mathrm{C} \\ \text { BBU } & \frac{\mathrm{CATC}}{\star \star \star \star} & 181 \mathrm{bp} & \mathrm{Tm}=88.9^{\circ} \mathrm{C}\end{array}$

\section{Figure 3}

Sequence variation of similarly-sized products. CLUSTAL W (v. I.83; [39]) alignment of IGFIR PCR product sequences of hamster (A23) and river buffalo (BBU). The primer sequences are underlined. Identical nucleotides are marked with an asterisk beneath. Product melting temperatures $\left(T_{m}\right)$ were estimated with Oligo 6 software, and while not identical to the melting curve generated by the SDS software, the relative differences in melt temperature between the buffalo and hamster products were similar for calculated and experimental values. Both methods indicated an approximate $2^{\circ} \mathrm{C}$ difference in $\mathrm{T}_{\mathrm{m}}$ which was sufficient for discrimination by dissociation curve analysis.

The remaining marker, AKT2, was the only marker to produce scorable data by gel-based typing alone, as a number of the RH clones exhibited dissociation curves that did not match either of the controls. The AKT2 primer set produced a river buffalo band of about 90 bp (expected size based on the cattle product) in the clones that were scored positive by gel electrophoresis, while the negative clones exhibited one or more bands other than the target that presumably muddled the qPCR data (Figure 5).

\section{RH map construction}

To further compare the two methods, we constructed separate RH maps of BBU20 from the qPCR- and gel-based scores. On the basis of qPCR scores, all 30 markers formed a single linkage group at LOD 7, of which 27 are included in the "qPCR map" (Figure 6A) that covers 92\% of the MARC linkage map of cattle chromosome 21 http:// www.marc.usda.gov/genome/cattle/cattle.html. The three remaining markers (RM151, BMS868, DIK2849) could not be reliably placed in a specific interval of the framework map. For the "gel map," 20 of 25 markers were included, but it was necessary to reduce the LOD score cutoff to 6.5 to have those 20 markers form a single linkage group (Figure 6B). Among markers common to both maps, the marker order was identical; i.e., slight differences in the marker scores had no effect on the optimal map order.

\section{Discussion}

Dissociation curve analysis is a viable alternative to conventional gel-based typing for RH mapping. In this case, primer sets chosen for RH mapping of river buffalo were based on sequence data from cattle, a related species. We expect that the method will be applicable to dissociation curve and high resolution melt analysis utilizing dyes such as SYTO 9, LCGreen, and EvaGreen in addition to the SYBR Green I utilized in this study. This mapping strategy allowed rapid genome mapping of our species of interest based on the existing high density marker map of the domestic cow. Markers for mapping were chosen more or less randomly to provide approximately even coverage of BTA21 microsatellite markers. We utilized a standardized PCR protocol without optimization to enable rapid, highthroughput gene mapping. Despite these constraints, we were able to type nearly half of the markers we tested, similar or slightly better than the success rate attained by our colleagues using conventional methods (e.g., [30]). Although greater success rates might have been achieved after PCR optimization for individual primer sets and a smaller proportion of microsatellite markers (e.g., [18]), our protocol reduced both time and resources spent identifying suitable markers by utilizing a single protocol.

Dissociation curve analysis is more robust than conventional typing. We typed $25 \%$ more markers by qPCR than 
$\mathbf{A}$

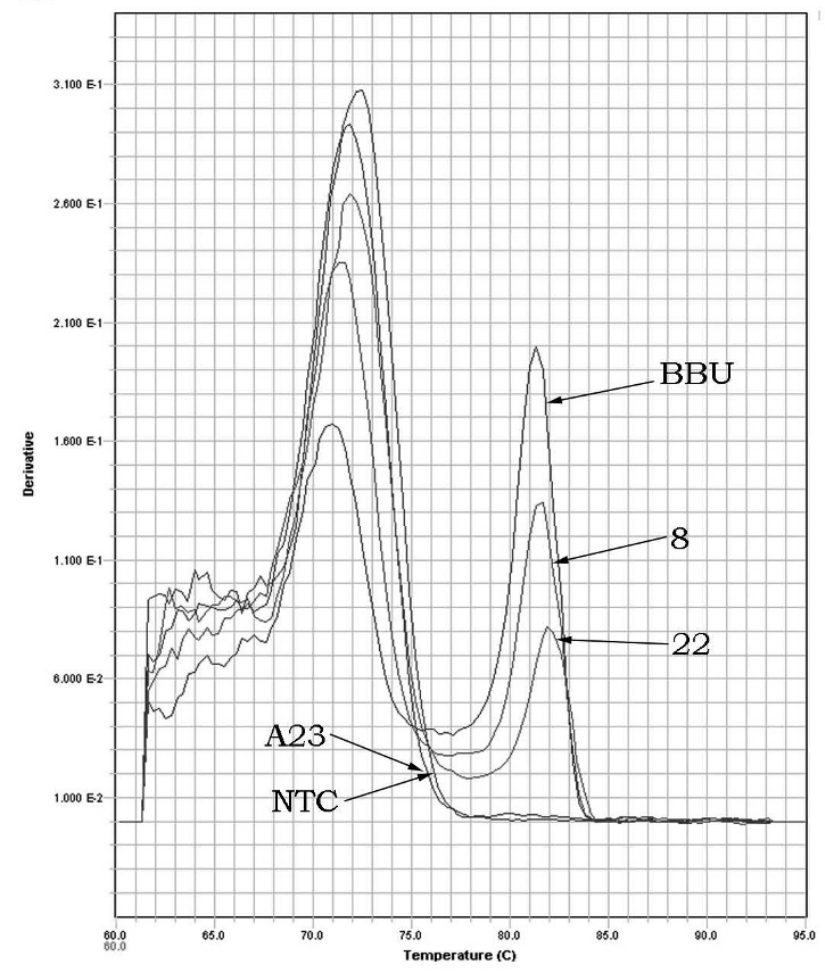

B

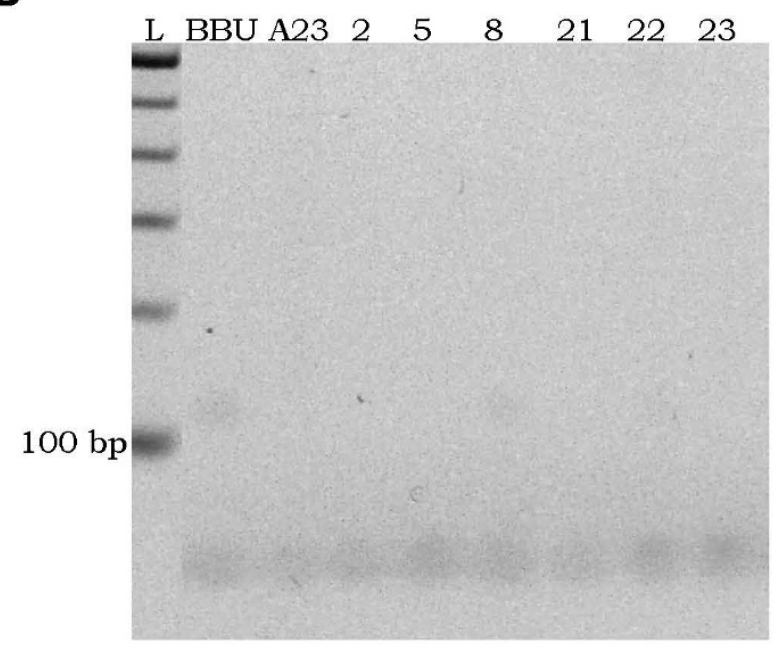

\section{Figure 4}

Sensitivity of qPCR method. Dissociation curve $(A)$ and gel image (B) of $R M / 5 I$ in buffalo (BBU), hamster (A23) and selected $\mathrm{RH}$ clones. The left peak on the dissociation curve is presumed to be primer-dimer ( $40 \mathrm{bp}$, as seen in the gel image), while the right peak is the target PCR product (barely visible or not at all in the gel image). This marker could not be scored by a gel-based method, but clones positive for buffalo DNA (\#8, \#22) are easily identified after dissociation curve analysis.
$\mathbf{A}$

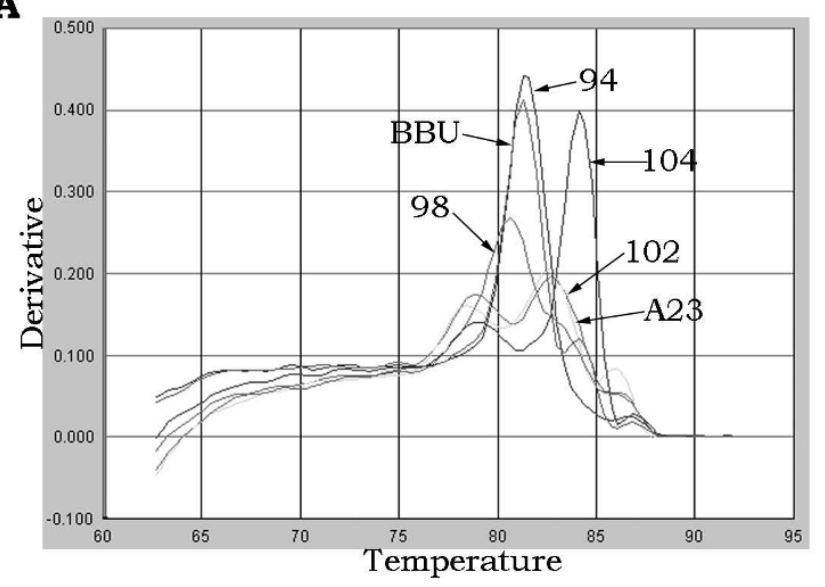

B

L BBU A2394959798100102 104

Figure 5

Ambiguous qPCR typing of $A K T 2$. Dissociation curve $(A)$ and gel image (B) of AKT2 in buffalo (BBU), hamster (A23) and selected RH clones. Most "positive" clones ( 90 bp target band present on gel) produced dissociation curves similar to the buffalo control (BBU, \#94, \#98) and most "negative" clones (target band absent on gel) produced dissociation curves similar to the hamster control (A23, \#102); however, a number of clones produced intermediate or shifted dissociation curves that could not be scored convincingly (e.g. \#104). Extraneous products and small target product size may have contributed to the variable dissociation curves for this marker.

by the gel-based method. While some of those markers might have yielded better gel-based data (i.e., stronger target bands) upon PCR optimization, qPCR data were produced without the use of additional time and resources necessary for optimization. Under conventional methods, some markers would have been discarded entirely without further consideration. The ability to differentiate PCR products not only by size, but also by sequence composition, is perhaps the greatest advantage of the qPCR method. Indeed, any means undertaken to increase the number of markers suitable for the gel-based map, such as 
A.

\section{BBU20 qPCR}

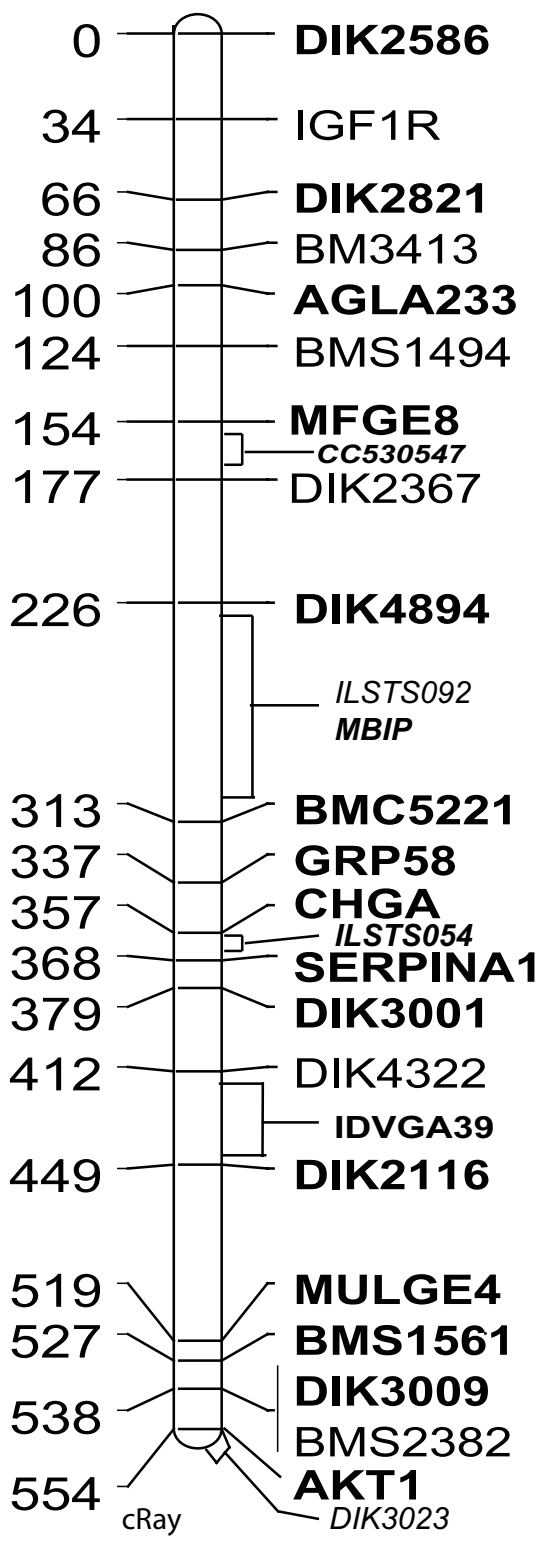

B.

BBU20 gel

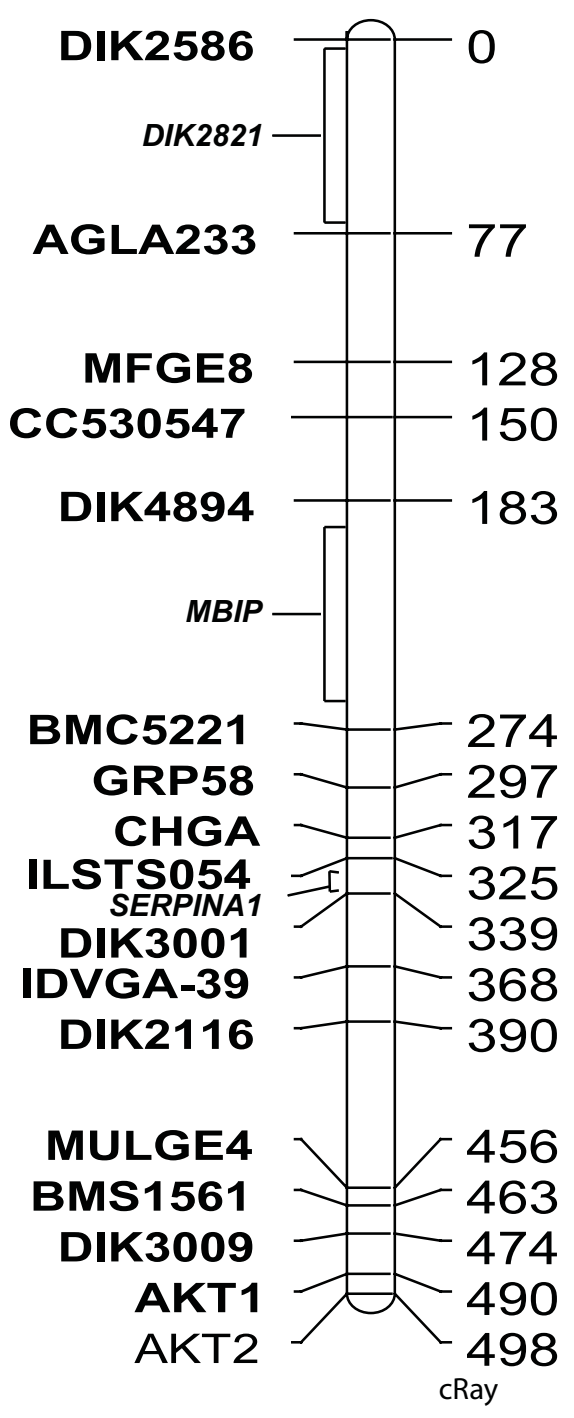

Figure 6

$\mathrm{BBU}_{5000} \mathrm{RH}$ map of BBU20 generated with dissociation curve data (A) and agarose gel electrophoresis data (B). Markers in plain text were placed only on one map, and those in bold were placed on both maps. Markers in italics were binned and not given a specific map location. 
a larger proportion of STS markers or coding genes, a requirement for well-designed primers (no hairpins or dimers, etc.), or optimization of the PCR protocol, would likely have led to a greater percentage of markers being included on the qPCR-based map.

The increased sensitivity of qPCR technology may reduce the incidence of scoring errors. Indirect evidence of more accurate scores is that $90 \%$ of the markers analyzed for the qPCR map ultimately comprised that map, compared to only $80 \%$ inclusion of analyzed markers in the linkage group for the gel map, even though the qPCR map used a higher LOD score threshold. Furthermore, among 25 markers typed on the agarose gels, individual clones were scored as questionable on a single PCR replicate due to faint bands or spurious bands of similar size to the target amplicon in 40 instances ( $1.8 \%$ of all scores). In contrast, among 30 markers typed by qPCR, only 21 instances ( $\sim 0.8 \%$ of all scores) of questionable results occurred in single replicates, generally due to shorter peaks for the buffalo product when the hamster product also amplified well. Conventional methods require duplicate typing to confirm accuracy and resolve questionable typing results. While qPCR technology does not completely eliminate the need for duplicate reactions, our observations indicate that qPCR typing may yield more accurate results than gelbased typing. Moreover, elimination of agarose gels removes the need for post-amplification handling and reduces opportunities for technical errors.

Typing data are generally scored as 1 (product present) or 0 (product absent), with questionable results scored as 2 . Reducing the number of ambiguous 2 scores is important because addressing ambiguous scores computationally remains controversial. During RH map computation, different software packages use different mathematical formulations of the maximum likelihood criterion when ambiguous scores are present in the data [31]. In this study, the presence of clones scored as 2 in these BBU20 data sets did not affect the map order or which markers could be retained, but the presence of $2 \mathrm{~s}$ in data for other maps we have computed has forced numerous markers to be dropped due to the ambiguity.

Among more than 2000 individual scores (based on duplicate reactions) from the 24 markers scored by both qPCR and gel electrophoresis, only 10 scores were discordant between the two methods. Two and 3 individual clones were scored as questionable by qPCR for DIK4894 and CC530547, respectively, due to intermediate dissociation curves. On the gel, each of these markers had distinct river buffalo and hamster bands clearly distinguishable by size. Most $\mathrm{RH}$ clones exhibited one band or the other, and these were in perfect accord with the qPCR data, but the questionable clones exhibited both bands (Figure 7). Two clones were also scored as questionable by qPCR for DIK2821, along with one questionable curve for IDVGA-39; all were scored positive on the gels, but consistently exhibited weak bands in comparison to the other positive clones (data not shown). Finally, two clones were scored as questionable for MFGE8 by gelbased typing due to the consistent presence of a faint band at the expected size. Both clones were clearly negative by qPCR, so the gel bands were sequenced. Neither sequence matched the expected product; in fact, neither band produced clean sequence, indicating that dissociation curve analysis yielded more accurate results in this instance. In this experiment, with only 20 markers on the map, scoring those two clones as ambiguous did not affect the placement of MFGE 8 on the map. As the river buffalo mapping project continues and the map becomes more

$\mathbf{A}$

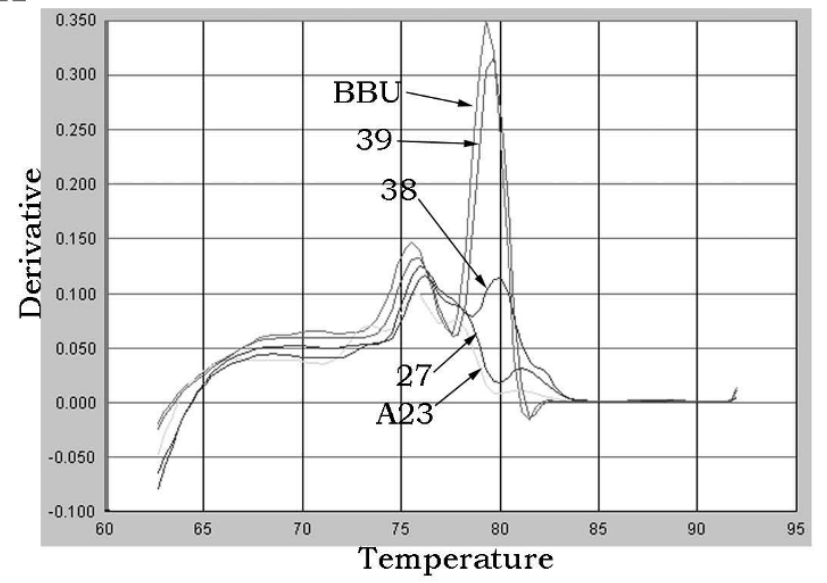

B

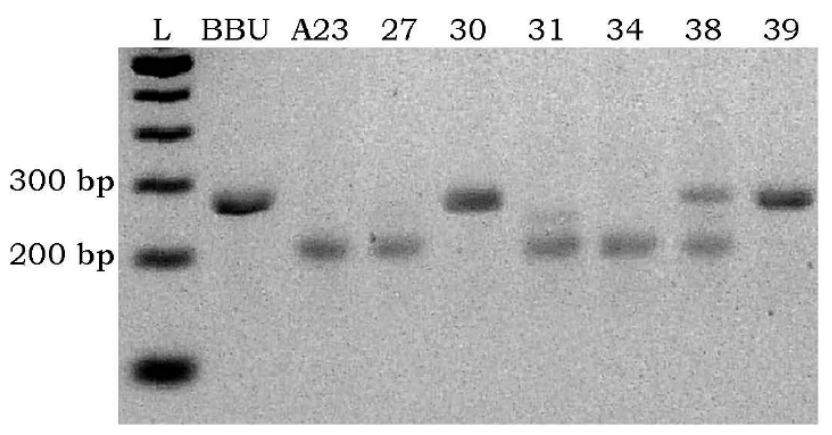

Figure 7

Amplification of hamster product reduces buffalo product peak size. Dissociation curve $(A)$ and gel image (B) of CC530547 in buffalo (BBU), hamster (A23) and selected $\mathrm{RH}$ clones. Clone \#38 produced a low, questionable peak on the dissociation curve, and unlike other positive clones (\#30 and \#39), exhibited the hamster band as well as the buffalo band in the gel. 
dense, similar errors could change the statistically optimal marker order.

Dissociation curve analysis utilizes fewer resources than conventional typing. While the actual cost of typing a single marker by either method may vary greatly depending on choice of particular reagents and plastic ware, we applied similar criteria to reagent selection for both methods and found similar costs for PCR amplification (not shown, but details can be provided by the corresponding author upon request). The beauty of the qPCR method is that elimination of post-amplification procedures (i.e., gels) reduces the labor time required to type each marker. At the same time, expense and hazardous waste associated with agarose gels and ethidium bromide staining procedures is eliminated.

Other non-conventional PCR-based methods have been applied to RH mapping including single-strand conformational polymorphism (PCR-SSCP; [32]), where PCR products can be differentiated based on sequence composition, and amplified length polymorphism (AFLP; [33]), which has the advantage of producing markers without any prior sequence information for the species of interest, but results in essentially anonymous markers. However, these methods and related techniques require post-amplification separation and visualization of products by radioisotopic labeling [32] or silver staining [34], which necessitates additional handling and disposal of hazardous materials. Fluorescence labeling [35] reduces hazardous materials but still requires time-consuming procedures for separation and visualization of PCR products.

High-throughput methods will have great utility for map construction. For example, McKay et al [36] computed a dense bovine RH map with Illumina Golden Gate technology. Once the effort to make the Illumina array is completed, all the markers can be genotyped rapidly. Thus, the cost per marker decreases greatly, but once the array design is completed, one cannot easily add individual markers of interest. For techniques such as those used by McKay et al, or for application of "next generation" sequencing technology, or utilization of SNP microarrays, the cost per sample is relatively low. However, startup costs remain high, and the volume of data to be processed must also be considered. For many species still lacking maps, suitable array-based tool are simply unavailable, emphasizing the importance of alternative methods for genotyping and map building. In practice, we have found that application of some of these methods to RH mapping is costly and data interpretation is not completely straightforward at this time (Amaral et al, unpublished). In contrast, assuming available instrumentation, startup cost to run a single marker by qPCR is the same cost as equivalent
PCR amplification, and likely more accessible to research groups involved in mapping species for which both gene maps and financial resources are currently limited.

The application of qPCR technology and fluorescence chemistry to DNA typing does impose limits on marker choice, particularly amplicon size. In this case, because SYBR Green I fluoresces upon laser excitation when bound to any double-stranded DNA, formation of primer-dimers may alter the dissociation curve of small $(<$ $100 \mathrm{bp}$ ) PCR products. Anecdotal evidence and our experience indicate that SYBR-based dissociation curves appear to be most reliable for product sizes greater than $100 \mathrm{bp}$. Some of the odd dissociation curves we observed with AKT2 may have been influenced by the small PCR product size ( $\sim 90 \mathrm{bp}$ ) of that marker. Indeed, it was the only marker that we attempted to type that was $<100 \mathrm{bp}$, and the only one that failed to produce clear, consistent results in the RH panel by qPCR. Large amplicons (> 500 bp) are not amplified as efficiently and may also produce inconsistent results. A brief survey of published RH maps indicates that PCR-based markers tend to fall in the range of 75-400 bp, with the majority ranging from 100-250 bp. In this experiment, the largest amplicon generated was 290 bp, so we did not observe any deleterious effects due to large product size. Ultimately the success of qPCR and subsequent dissociation curve analysis relies on the use of well-designed primers that clearly amplify a single product. Furthermore, PCR products of different sizes may have similar melting temperatures. For example, BM846 amplified two products from river buffalo DNA, as shown in the agarose gel, but displayed a single dissociation peak (data not shown). We excised and sequenced both products visualized in the gel and calculated that the melting temperatures of the two products were within $1{ }^{\circ} \mathrm{C}$ of each other, but amplicons did not appear to represent alleles of the same gene. Therefore, it may still be beneficial to test primer sets by visualizing control reactions via gel electrophoresis to ensure the presence of a single PCR product before proceeding with mapping.

\section{Conclusion}

In summary, we developed a new method of marker scoring for RH maps. SYBR Green I-based qPCR and dissociation curve analysis offered greater sensitivity than the conventional gel-based scoring method, for detection of differences between buffalo and hamster products as well as reduction of scoring errors. To prove that this method can lead to better maps faster, we generated maps of river buffalo chromosome 20 using both old and new methods. The qPCR map contained 35\% more markers and was based on a higher LOD score cutoff than the gel-based map. We have demonstrated that this novel application of dissociation curve analysis provides a reliable and efficient improvement over conventional methods for 
marker scoring in any species where $\mathrm{RH}$ mapping panels are available. Marker scoring remains the most laborintensive step in RH map development. This sensitive method of qPCR-based marker scoring should enable faster construction of RH maps. As high-throughput methods are being developed for cross-species analysis, this method will remain a useful adjunct mapping tool.

\section{Methods \\ Marker Selection}

Fifty microsatellite markers and 9 genes or sequence tagged sites (STS) were selected to span the entire BTA21 chromosome map at intervals less than $5 \mathrm{cM}$. Most markers had published PCR annealing temperatures within $58-62^{\circ} \mathrm{C}$, and were chosen from maps maintained by MARC http://www.marc.usda.gov/genome/cattle/cat tle.html, ENSEMBL http://www.ensembl.org/Bos taurus/ index.html, and NCBI http://www.ncbi.nlm.nih.gov/ mapview/map search.cgi?taxid=9913. Six additional primer sets were designed with Oligo 6 software (Molecular Biology Insights, Inc., Cascade, CO) to anchor the RH map to the river buffalo cytogenetic map (CHGA, SERPINA1, and GRP58; [37]), and to increase the number of named genes on the map (IGF1R, MESDC2 and MFGE8). All markers were tested on DNA from a B. taurus bull (positive control for the markers), a river buffalo bull and Chinese hamster A23 cells (representing the donor and recipient species of the $\mathrm{RH}$ clones, respectively) by both qPCR and agarose gel analysis. Markers that amplified well in the river buffalo DNA and exhibited different dissociation curves between buffalo and hamster were used for typing the DNA from 90 RH panel clones [18].

\section{Real-time PCR and dissociation curve analysis}

Real-time PCR was performed in a $20 \mu$ reaction containing 20 ng template DNA, $1 \times$ Power SYBR Green PCR master mix (Applied Biosystems, Foster City, CA) and $300 \mathrm{nM}$ primers. Amplification was carried out in 96-well plates in either a $7900 \mathrm{HT}$ or a 7500 sequence detection system (Applied Biosystems) with the manufacturer's default thermal profile $\left(50^{\circ} \mathrm{C}\right.$ for 2 minutes, $95^{\circ} \mathrm{C}$ for $10 \mathrm{~min}$ utes, and 40 cycles of $95^{\circ} \mathrm{C}$ for 15 seconds and $60^{\circ} \mathrm{C}$ for 1 minute) followed by a dissociation stage $\left(95^{\circ} \mathrm{C}\right.$ for $15 \mathrm{sec}$ onds, $60^{\circ} \mathrm{C}$ for 15 seconds, followed by a slow ramp to $95^{\circ} \mathrm{C}$ ). The incubation at $50^{\circ} \mathrm{C}$ was not necessary, but the instrument's default profile was intentionally not changed. For analysis in 384-well format, $10 \mu \mathrm{l}$ reactions containing $10 \mathrm{ng}$ template DNA were prepared with a Precision 2000 Plus automated microplate pipetting system (Bio-Tek Instruments, Inc., Winooski, VT) and amplified in a 7900 HT sequence detection system with the same thermal profile as described above. Amplification and dissociation data were analyzed with SDS software v.2.2.2 (Applied Biosystems) as described by Ririe et al. [29]. Radiation hybrid clones were scored independently by two people for presence or absence of the peak representing the river buffalo product. The scores were compared and discrepancies that were not clerical errors were scored as questionable.

\section{Agarose gel electrophoresis}

Real-time PCR products were separated by electrophoresis on $2 \%$ SFR agarose gels (Amresco, Inc., Solon, OH). Digital images of the gels were captured using an Electrophoresis Documentation and Analysis System 290 (EDAS 290; Kodak, New Haven, CT). Gel images were scored in the same manner as, and independently from, the dissociation curve data.

\section{Sequencing}

DNA was amplified by conventional PCR using $50 \mathrm{ng}$ template DNA in a $50 \mu \mathrm{l}$ reaction containing $3 \mathrm{U}$ AmpliTaq Gold polymerase (Applied Biosystems, Foster City, $\mathrm{CA}$ ), $3.0 \mathrm{mM}$ magnesium chloride and $300 \mathrm{nM}$ primers. Amplification was carried out in an ABI 2720 thermal cycler (Applied Biosystems) with an initial denaturation at $95^{\circ} \mathrm{C}$ for 5 minutes, followed by 35 cycles of $95^{\circ} \mathrm{C}$ for 15 seconds and $60^{\circ} \mathrm{C}$ for 1 minute. The products were purified through PSIYClone PCR 96 columns (Princeton Separations, Adelphia, NJ). Sequencing was performed following PCR amplification in a $10 \mu$ reaction containing $50 \mathrm{ng}$ template DNA, $0.75 \times$ sequencing buffer, 500 $\mathrm{nM}$ primers and $1 \mathrm{ul}$ BigDye $\mathrm{v} 1.1$ sequencing master mix (Applied Biosystems) with an initial denaturation at $98^{\circ} \mathrm{C}$ for 2 minutes, followed by 25 cycles of $96^{\circ} \mathrm{C}$ for $10 \mathrm{sec}$ onds, $50^{\circ} \mathrm{C}$ for 5 seconds and $60^{\circ} \mathrm{C}$ for 4 minutes. After purification through DyeEx spin columns (Qiagen, Valencia, CA) and resuspension in $10 \mu$ deionized formamide, sequences of PCR products were determined with a 3130 $\times 1$ Genetic Analyzer (Applied Biosystems) and data were analyzed with Sequence Analysis v5.2 software (Applied Biosystems). Melting temperatures of the PCR product sequences were calculated in Oligo 6 software.

\section{Map computation}

For each of the two sets of marker scores, maps of BBU20 were computed using the maximum likelihood criterion with the software rh_tsp_map v3.0 ([24,31]; ftp:// ftp.ncbi.nlm.nih.gov/pub/agarwala/rhmapping/

rh tsp map.tar.gz) and CONCORDE [38] linked to Qsopt http://www2.isye.gatech.edu/ w wcook/qsopt/. The same general method was used to compute earlier maps of BBU chromosomes $[18,22,28,30]$. Frame markers passed a flips test at LOD threshold 0.5 and were assigned centiRay (cR) positions on the map. Some markers were placed in bins - intervals between frame markers - based on best order and passing flips at LOD threshold 0.5 within the bin, but with odds too low to establish $\mathrm{cR}$ positions. Markers that were not frame markers and could not be placed were dropped. In the qPCR map, markers DIK3009 
and BMS2382 have identical scores and hence identical positions.

\section{Authors' contributions}

KJK contributed to the design of the study, produced and analyzed RH scoring and sequencing data, and drafted the manuscript. MEJA provided the RH panel DNA, prepared data for map computation, and contributed to the design of the study. RA and AAS performed the mapping computations and helped draft the manuscript. PKR conceived and led the project, scored and analyzed RH data, and helped draft the manuscript. All authors read and approved the final manuscript.

\section{Additional material}

\section{Additional file 1}

Markers tested but not used for mapping. This table is a list of markers that were tested but not used for mapping.

Click here for file

[http://www.biomedcentral.com/content/supplementary/1471-

2164-9-544-S1.xls]

\section{Additional file 2}

Comparison of marker typing and scoring by both methods. A comparison of the number of markers found suitable for typing and scoring by either method is presented as a table in Additional File 2.

Click here for file

[http://www.biomedcentral.com/content/supplementary/14712164-9-544-S2.doc]

\section{Acknowledgements}

We thank Jooha Jeong, A. J. Greco, Colette Abbey, Ashley Gustafson-Seabury, and Robert E. King for technical assistance, and Alan R. Silverman for use of an ABI 7500 Sequence Detection System. This work was supported in part by Texas A\&M AgriLife Research project RI-9I92 (P.K.R.), and in part by the Intramural Research Program of the National Institutes of Health, NLM (R.A., A.A.S). The BBURH ${ }_{5000}$ panel DNA was provided by M.E.J.A. and James E. Womack. Original construction of the $B B U R H_{5000}$ panel was supported by grants from FAPESP-Brazil (02/I0I50-5) to M.E.J.A. and NSF-USA (OISE-0405743) to J.E.W.

\section{References}

I. Dalla Valle L, Toffolo V, Lamprecht M, Maltese C, Bovo G, Belvedere $P$, Colombo L: Development of a sensitive and quantitative diagnostic assay for fish nervous necrosis virus based on twotarget real-time PCR. Vet Microbiol 2005, I I 0(3-4): I67-I 79.

2. Martorell P, Querol A, Fernández-Espinar MT: Rapid identification and enumeration of Saccharomyces cerevisiae cells in wine by real-time PCR. Appl Environ Microbiol 2005, 7 I ( I I ):6823-6830.

3. Vandenbroucke II, Vandesompele J, Paepe AD, Messiaen L: Quantification of splice variants using real-time PCR. Nucleic Acids Res 200I, 29(I3):E68-68.

4. Mitre\&\#x0I0D;i\&\#x0107;; D, Huzak M, urlin M, Gajovi\&\#x0107; S: An improved method for determination of gene copy numbers in transgenic mice by serial dilution curves obtained by real-time quantitative PCR assay. J Biochem Biophys Methods 2005, 64(2):83-98.

5. Sangkitporn SK, Wangkahat K, Sangnoi A, Songkharm B, Charoenporn P, Sangkitporn S: Rapid diagnosis of $\alpha^{0}$-thalassemia using the relative quantitative $P C R$ and the dissociation curve analysis. Clin Lab Haematol 2003, 25(6):359-365.

6. Akey JM, Sosnoski D, Parra E, Dios S, Hiester K, Su B, Bonilla C, Jin L, Shriver MD: Melting curve analysis of SNPs (McSNP): a gelfree and inexpensive approach for SNP genotyping. Biotechniques 200I, 30(2):358-367.

7. Goss SJ, Harris H: New method for mapping genes in human chromosomes. Nature 1975, 255(55 I I):680-684.

8. Cox DR, Burmeister M, Price ER, Kim S, Myers RM: Radiation hybrid mapping: a somatic cell genetic method for constructing high-resolution maps of mammalian chromosomes. Science 1990, 250(4978):245-250.

9. Walter MA, Spillett DJ, Thomas P, Weissenbach J, Goodfellow PN: A method for constructing radiation hybrid maps of whole genomes. Nat Genet 1994, 7( I):22-28.

10. Marques E, de Givry S, Stothard P, Murdoch B, Wang Z, Womack JE, Moore SS: A high resolution radiation hybrid map of bovine chromosome I4 identifies scaffold rearrangement in the latest bovine assembly. BMC Genomics 2007, 8:254.

II. Womack JE, Johnson JS, Owens EK, Rexroad CE 3rd, Schlapfer J, Yang YP: A whole-genome radiation hybrid panel for bovine gene mapping. Mamm Genome I997, 8(I I):854-856.

12. Hawken RJ, Murtaugh J, Flickinger GH, Yerle M, Robic A, Milan D, Gellin J, Beattie CW, Schook LB, Alexander LJ: A first-generation porcine whole-genome radiation hybrid map. Mamm Genome 1999, I 0(8):824-830.

13. Morisson M, Lemiere A, Bosc S, Galan M, Plisson-Petit F, Pinton P, Delcros C, Fève K, Pitel F, Fillon V, et al.: ChickRH6: a chicken whole-genome radiation hybrid panel. Genet Sel Evol 2002, 34(4):52 I-533.

14. Chowdhary BP, Raudsepp T, Honeycutt D, Owens EK, Piumi F Guérin G, Matise TC, Kata SR, WomackJE, Skow LC: Construction of a $5^{2000}$ rad whole-genome radiation hybrid panel in the horse and generation of a comprehensive and comparative map for ECAI I. Mamm Genome 2002, I3(2):89-94.

15. Everts-van der Wind A, Kata SR, Band MR, Rebeiz M, Larkin DM, Everts RE, Green CA, Liu L, Natarajan S, Goldammer T, et al.: A I 463 gene cattle-human comparative map with anchor points defined by human genome sequence coordinates. Genome Res 2004, I 4(7): | 424-|437.

16. Everts-van der Wind A, Larkin DM, Green CA, Elliott JS, Olmstead CA, Chiu R, Schein JE, Marra MA, Womack JE, Lewin HA: A highresolution whole-genome cattle-human comparative map reveals details of mammalian chromosome evolution. Proc Natl Acad Sci USA 2005, I 02(5 I): |8526-18531.

17. Wu CH, Nomura K, Goldammer T, Hadfield T, Womack JE, Cockett NE: An ovine whole-genome radiation hybrid panel used to construct an RH map of ovine chromosome 9. Anim Genet 2007, 38(5):534-536.

18. Amaral MEj, Owens KE, Elliott JS, Fickey C, Schäffer AA, Agarwala R, Womack JE: Construction of a river buffalo (Bubalus bubalis) whole-genome radiation hybrid panel and preliminary $\mathbf{R H}$ mapping of chromosomes 3 and I0. Anim Genet 2007, 38(3):3 ||$-3 \mid 4$

19. Boyazaglu J: Topical Review. Livestock Production Science 1997, 48:71-75.

20. Bernardes O: Buffaloes breeding in Brasil. Italian Journal of Animal Science 2007, 6(Suppl 2): 162-167.

21. Cruz LC: Trends in buffalo production in Asia. Italian Journal of Animal Science 2007, 6(Suppl 2):9-24.

22. Stafuzza NB, lanella P, Miziara MN, Agarwala R, Schäffer AA, Riggs PK, Womack JE, Amaral MEJ: Preliminary radiation hybrid map for river buffalo chromosome 6 and comparison to bovine chromosome 3. Anim Genet 2007, 38(4):406-409.

23. Murphy WJ, O'Brien SJ: Designing and optimizing comparative anchor primers for comparative gene mapping and phylogenetic inference. Nat Protoc 2007, 2(I I):3022-3030.

24. Schäffer AA, Rice ES, Cook W, Agarwala R: rh_tsp_map 3.0: endto-end radiation hybrid mapping with improved speed and quality control. Bioinformatics 2007, 23(9): I I 56- I I 58

25. Gyapay G, Schmitt K, Fizames C, Jones H, Vega-Czarny N, Spillett D, Muselet D, Prud'Homme J-F, Dib C, Auffray C, et al.: A radiation hybrid map of the human genome. Hum Mol Genet 1996, 5(3):339-346. 
26. Rexroad CE 3rd, Schlapfer JS, Yang Y, Harlizius B, Womack JE: A radiation hybrid map of bovine chromosome one. Anim Genet 1999, 30(5):325-332.

27. lannuzzi L, Di Meo GP, Perucatti A, Ferrara L: The high resolution G- and R-banding pattern in chromosomes of river buffalo (Bubalus bubalis L.). Hereditas 1990, I I 2(3):209-2I 5.

28. Miziara MN, Goldammer T, Stafuzza NB, lanella $P$, Agarwala $R$ Schäffer AA, Elliott JS, Riggs $P K$, Womack JE, Amaral MEJ: A radiation hybrid map of river buffalo (Bubalus bubalis) chromosome I (BBUI). Cytogenet Genome Res 2007, I I 9( I-2): I00-I04.

29. Ririe KM, Rasmussen RP, Wittwer CT: Product differentiation by analysis of DNA melting curves during the polymerase chain reaction. Anal Biochem 1997, 245(2): I54-I60.

30. Goldammer T, Weikard R, Miziara MN, Brunner RM, Agarwala R, Schäffer AA, Womack JE, Amaral MEJ: A radiation hybrid map of river buffalo (Bubalus bubalis) chromosome 7 and comparative mapping to the cattle and human genomes. Cytogenet Genome Res 2007, I I 9(3-4):235-24I.

31. Agarwala R, Applegate DL, Maglott D, Schuler GD, Schäffer AA: A fast and scalable radiation hybrid map construction and integration strategy. Genome Res 2000, I0(3):350-364.

32. Miller CL, Thompson RC, Burmeister M: Radiation hybrid mapping of the two highly homologous human-variant pMCHL genes by PCR-SSCP. Genome Res 1998, 8(7):737-740.

33. Gorni C, Williams JL, Heuven HC, Negrini R, Valentini A, van Eijk MJ, Waddington D, Zevenbergen M, Marsan PA, Peleman JD: Application of AFLP technology to radiation hybrid mapping. Chromosome Res 2004, I 2(3):285-297.

34. Lahbib-Mansais Y, Dalias G, Milan D, Yerle M, Robic A, Gyapay G, Gellin J: A successful strategy for comparative mapping with human ESTs: 65 new regional assignments in the pig. Mamm Genome 1999, I0(2): 145-153.

35. Herbergs J, Siwek M, Crooijmans RP, Poel JJ Van der, Groenen MA: Multicolour fluorescent detection and mapping of AFLP markers in chicken (Gallus domesticus). Anim Genet 1999, 30(4):274-285.

36. McKay SD, Schnabel RD, Murdoch BM, Aerts J, Gill CA, Gao C, Li C, Matukumalli LK, Stothard P, Wang Z, et al.: Construction of bovine whole-genome radiation hybrid and linkage maps using highthroughput genotyping. Anim Genet 2007, 38(2): I20-I25.

37. lannuzzi L, Di Meo GP, Perucatti A, Schibler L, Incarnato D, Gallagher $D$, Eggen A, Ferretti L, Cribiu EP, Womack JE: The river buffalo (Bubalus bubalis, $2 n=50$ ) cytogenetic map: assignment of 64 loci by fluorescence in situ hybridization and R-banding. Cytogenet Genome Res 2003, I 02( I-4):65-75.

38. Applegate DL, Bixby R, Chvátal V, Cook W: The Traveling Salesman Problem: A Computational Study. Princeton, NJ, USA: Princeton University Press; 2006.

39. Chenna R, Sugawara H, Koike T, Lopez R, Gibson TJ, Higgins DG, Thompson JD: Multiple sequence alignment with the Clusta series of programs. Nucleic Acids Res 2003, 3 I ( I 3):3497-3500.

40. Ihara N, Takasuga A, Mizoshita K, Takeda H, Sugimoto M, Mizoguchi Y, Hirano T, Itoh T, Watanabe T, Reed KM, et al.: A comprehensive genetic map of the cattle genome based on $\mathbf{3 8 0 2}$ microsatellites. Genome Res 2004, I 4( I OA): I 987-1998.

41. Fahrenkrug SC, Freking BA, Rexroad CE 3rd, Leymaster KA, Kappes SM, Smith TP: Comparative mapping of the ovine clpg locus. Mamm Genome 2000, I I ( I 0):87I-876.

42. Bishop MD, Kappes SM, Keele JW, Stone RT, Sunden SLF, Hawkins GA, Solinas Toldo S, Fries R, Grosz MD, Yoo J, et al:: A genetic linkage map for cattle. Genetics 1994, I36(2):619-639.

43. Stone RT, Pulido JC, Duyk GM, Kappes SM, Keele JW, Beattie CW: A small-insert bovine genomic library highly enriched for microsatellite repeat sequences. Mamm Genome 1995, 6(10):7|4-724.

44. Kappes SM, Keele JW, Stone RT, McGraw RA, Sonstegard TS, Smith TPL, Lopez-Corrales NL, Beattie CW: A second-generation linkage map of the bovine genome. Genome Res 1997, 7(3):235-249.

45. Mezzelani A, Zhang Y, Redaelli L, Castiglioni B, Leone P, Williams JL, Solinas Toldo S, Wigger G, Fries R, Ferretti L: Chromosomal localization and molecular characterization of 53 cosmid-derived bovine microsatellites. Mamm Genome 1995, 6(9):629-635.

46. Kemp SJ, Hishida O, Wambugu J, Rink A, Longeri ML, Ma RZ, Da Y, Lewin HA, Barendse W, Teale AJ: A panel of polymorphic bovine, ovine and caprine microsatellite markers. Anim Genet 1995, 26(5):299-306.
47. Berghmans S, Segers K, Shay T, Georges M, Cockett N, Charlier C: Breakpoint mapping positions the callipyge gene within a 450-kilobase chromosome segment containing the DLKI and GTL2 genes. Mamm Genome 200।, I 2(2): | 83- |85.

48. McGraw RA, Grosse WM, Kappes SM, Beattie CW, Stone RT: Thirty-four bovine microsatellite markers. Anim Genet 1997, 28(I):66-68.
Publish with Biomed Central and every scientist can read your work free of charge

"BioMed Central will be the most significant development for disseminating the results of biomedical research in our lifetime. "

Sir Paul Nurse, Cancer Research UK

Your research papers will be:

- available free of charge to the entire biomedical community

- peer reviewed and published immediately upon acceptance

- cited in PubMed and archived on PubMed Central

- yours - you keep the copyright

Submit your manuscript here:

http://www.biomedcentral.com/info/publishing_adv.asp
BioMedcentral 